\title{
Effects of Physical Activity on Controlling Blood Pressure Among Hypertensive Patients at the Region of Prizren
}

\author{
PhD, MD, Nderim Rizanaj \\ MSc, BSc Agron Bytyqi
}

\begin{abstract}
Aim: To describe the effect of physical activity on controlling blood pressure among hypertensive patients at Region of Prizren. Method: A sample of 101 patients diagnosed with hypertension in the region of Prizren, which were randomly selected from those hypertensive patients who visited the Main Family Medicine Centre and Private ambulance "Nderimed" for their regular follow up. A structured questionnaire (Life Style Questionnaire and Perceived Stress Scale) with questions on different characteristics was administered. In terms of gender composition there were 41 men and 49 women, aged between 45 and 74 years old. Result: Among our sample just $7.8 \%$ reported that they make physical activity regularly. $68 \%$ of the sample reported that they engaged less than one hour per week in some kind of activity and their motivation to do so was also weak, just half of them report that they want to lose in weight. When participants were asked how many hours they move by walk or bike, with 0 hours reported $69 \%$. Conclusion: The increased risk of physical inactivity in controlling hypertension in this study suggests that general practitioners must be in the habit of prescribing practice of physical exercise and patients are followed up regularly to confirm that they are adhering to the management plan and the blood pressure targets are being met.
\end{abstract}

Keywords: physical activity, hypertension, risk factors.

\section{Introduction}

Similarly, the lack of physical activity also represents a major health problem related to several diseases and even death rates. Thus according to the WHO report, an estimated 1.9 million deaths are attributable to physical inactivity annually worldwide.[2] Approximately one third of adults are not physically active at all.[3] Studies have demonstrated that physical inactivity increases with age and is more prevalent among females.[7] Physical inactivity itself is an important independent risk factor of many chronic diseases such as hypertension, diabetes mellitus and heart diseases; also it significantly increases the risk of cardiovascular diseases. $[3,6]$

To summarize unhealthy diets along with physical inactivity are two of the main risk factors of many chronic diseases, including hypertension. [5, 6] According to National Institute of Public Health of Kosova (NIPH) $77 \%$ of the overall population in Kosovo suffers from hypertension; this disease also represents $57 \%$ of causes of deaths in the country [1]. Although a healthy diet and moderate physical activity are related to better management of hypertension, very little attention is being paid to these two aspects. $[4,6]$

\section{Aim/Purpose}

The purpose of this study is to describe the effect of physical activity on controlling blood pressure, in a sample of patients with hypertension in Region of Prizren.

\section{Methodology}

\section{Sample}

Participants were 101 patients diagnosed with hypertension in the region of Prizren, which were randomly selected from those hypertensive patients who visited the Main Family Medicine Centre and Private ambulance "Nderimed" for their regular follow up. A structured questionnaire (Life Style Questionnaire and Perceived Stress Scale) with questions on 
different characteristics was administered. In terms of gender composition there were 41 men and 49 women, aged between 45 and 74 years old.

In terms of education level, $12(11.9 \%)$ of them were with four classes completed, $64(63.4 \%)$ of them were with primary school, $5(5 \%)$ of them were with secondary school, $3(3 \%)$ of them were with university degree, $5(5 \%)$ of them were with master degree and 1 with doctoral degree. Also as regards marital status, all patients were married except for one who was divorced.

\section{Data collection and Design}

This study was cross sectional and descriptive in nature. The methods of data collection comprised of personal interview and physical assessment (anthropometric and blood pressure measurements). A standardized, semi-structured, interviewer administered questionnaire (Life Style Questionnaire and Perceived Stress Scale) was used to obtain information on the socio-demographic characteristics of the study participants, dietary pattern and lifestyle. The questionnaire also included 13 questions on physical activity; examples were 'Do you exercise regularly', 'How many times in week you walk or bike', How much you feel motivated to make exercise' etc.

\section{Data analyses}

Data was analyzed using the statistical package for social sciences (SPSS) version 21 computer statistical software package. Frequency distribution tables were constructed; cross tabulations were done to examine relationship between categorical variables. The Chi-square test was used to compare differences between proportions. Logistic regression analysis was used to determine the variables that predict nutrition status and hypertension among the participants. All statistical analysis was set at $5 \%$ level of significance $(p<0.05)$.

\section{Results}

Among our sample just $7.8 \%$ reported that they make physical activity regularly. $68 \%$ of the sample reported that they engaged less than one hour per week in some kind of activity and their motivation to do so was also weak, just half of them report that they want to lose in weight. When participants were asked how many hours they move by walk or bike, with 0 hours reported $69 \%$.

As demonstrated on the table below most of the sample was often motivated (Mean=1.86, where 1 always, 2 often, 3 sometimes and 4 never) to exercise, but in reality they don't exercise ( $82.2 \%$ say no as demonstrated on Table 2$)$.

Table 1. Descriptive Statistics

\begin{tabular}{|l|l|l|l|l|l|}
\hline $\mathrm{N}$ & Min & Max & Mean & Std. Deviation \\
\hline $\begin{array}{l}\text { Do you usually feel motivated to exercise? } \\
\text { Valid N }\end{array}$ & 1.00 & 4.00 & 1.8605 & 82836 \\
86 & & & & \\
\hline
\end{tabular}

Table 2. Do you exercise regularly?

\begin{tabular}{|c|l|l|l|l|}
\hline & Frequency & Percent & Valid Percent & Cumulative Percent \\
\hline Yes & 7 & 6.9 & 7.8 & 7.8 \\
Valid No & 83 & 82.2 & 92.2 & 100.0 \\
Total & 90 & 89.1 & 100.0 & \\
MissingSystem & 11 & 10.9 & & \\
Total & 101 & 100.0 & & \\
\hline
\end{tabular}

\section{Conclusion}

The increased risk of physical inactivity in controlling hypertension in this study suggests that general practitioners must be in the habit of prescribing practice of physical exercise and patients are followed up regularly to confirm that they are adhering to the management plan and the blood pressure targets are being met.

Findings seem to be quite problematic in terms of health behaviors displayed by patients with hypertension. Patients seem to engage very little in physical exercise besides other unhealthy life style. However it is not clear from the findings of the 
study whether this unhealthy life style is due to lack of knowledge (they are not educated about the importance of engaging in physical exercise or other life style importance) or lack of motivation to do so (despite knowledge). Moreover, the involvement of culture specific factors might also be examined; e.g., red meat being part of the typical diet in Kosovo. Nonetheless these findings suggest the need to inform and educate patients into following a proper diet and physical activity regimen, two aspects which are crucial in keeping the condition under control. The implications are clear for health professionals dealing with these patients, especially in providing life-style advice and support. In this context future research might be suggested which investigates the real reasons behind these findings especially in terms of the roles that health professionals have in this process; for instance health professionals might be asked on the type of medical advice they provide to these patients and conversely patients might be asked the same about doctors. To conclude, despite the limitations (small sample, descriptive data etc.) the present study provides some important directions for future research.

\section{References}

[1] National Institute of Public Health of Kosova, Morbidity analyses of population in Kosovo for 2011y (alb. Analiza e morbiditetit te popullates se Kosoves per vitin 2011), available from http://www.niphkosova.org/index.php?option=com jidownloads\&ltemid=6\&view=view.download\&catid=3\&cid $=58$

[2] Shephard RJ, Balady GJ. Exercise as cardiovascular therapy. Circulation. 1999;99:963-72.

[3] Pescatello LS, Franklin BA, Fagard R, Farqijar WB, Kelley GA, Ray CA. Exercise and hypertension: American College of Sports Medicine, Position Stand. MedSci Sports Exerc. 2004;36:533-52.

[4] World Health Organization, Diet and physical activity: a public health priority [online], available from http://www.who.int/dietphysicalactivity/en/

[5] Volterrani M., Lellamo F. "Effect of exercise training in essential arterial hypertension", $\mathrm{Rev} \mathrm{Br}$ as Hiper tens vol.17(2):68-71, 2010.

[6] Juríková J, Novotná E, Šitinová M. "eating habits and frequency of physical activity in hypertonic patients", bromat. Chem. TOKSYKOL. - XLV, 2012, 3, str. 1035-1038

[7] Alsairaf M., Alshamali K., Al-rashed A. "Effect of Physical Activity on Controlling Blood Pressure among Hypertensive Patients from Mishref Area of Kuwait", Mishref Clinic, Hawalli Health District, Kuwait, Eur J Gen Med 2010;7(4):377-384 